\title{
Male mice that lack the G-protein-coupled receptor GPR41 have low energy expenditure and increased body fat content
}

\author{
Mohamed Bellahcene ${ }^{1} t$, Jacqueline F. O’Dowd ${ }^{1}$, Ed T. Wargent ${ }^{1}$, Mohamed S. Zaibi ${ }^{1}$, David C. Hislop ${ }^{1}$, \\ Robert A. Ngala ${ }^{1} \neq$, David M. Smith ${ }^{2}$, Michael A. Cawthorne ${ }^{1}$, Claire J. Stocker ${ }^{1}$ and Jonathan R. S. Arch ${ }^{1 *}$ \\ ${ }^{1}$ Clore Laboratory, University of Buckingham, Buckingham MK18 1EG, UK \\ ${ }^{2}$ Astrazeneca, Alderley Park, Macclesfield, Cheshire SK10 4TF, UK
}

(Submitted 15 December 2011 - Final revision received 6 June 2012 - Accepted 1 August 2012 - First published online 31 October 2012 )

\section{Abstract}

SCFA are produced in the gut by bacterial fermentation of undigested carbohydrates. Activation of the $G \alpha_{\mathrm{i}}$-protein-coupled receptor GPR 41 by SCFA in $\beta$-cells and sympathetic ganglia inhibits insulin secretion and increases sympathetic outflow, respectively. A possible role in stimulating leptin secretion by adipocytes is disputed. In the present study, we investigated energy balance and glucose homoeostasis in GPR41 knockout mice fed on a standard low-fat or a high-fat diet. When fed on the low-fat diet, body fat mass was raised and glucose tolerance was impaired in male but not female knockout mice compared to wild-type mice. Soleus muscle and heart weights were reduced in the male mice, but total body lean mass was unchanged. When fed on the high-fat diet, body fat mass was raised in male but not female GPR41 knockout mice, but by no more in the males than when they were fed on the low-fat diet. Body lean mass and energy expenditure were reduced in male mice but not in female knockout mice. These results suggest that the absence of GPR 41 increases body fat content in male mice. Gut-derived SCFA may raise energy expenditure and help to protect against obesity by activating GPR41.

\section{Key words: G-protein-coupled receptor 41: Body composition: Energy expenditure: Glucose tolerance}

The gut contains sensors for a wide range of nutrients, a number of them being G-protein-coupled receptors (GPCR/ GPR). Among these GPCR are a group that respond to fatty acids, including GPR40 (FFA1), GPR43 (FFA2), GPR84 and GPR120 ${ }^{(1-3)}$. GPR41 (FFA3) is a GPCR that is activated by SCFA $^{(4,5)}$. GPR43 is the only other member of this group that is activated by SCFA; GPR42, which is expressed in some human subjects ${ }^{(6)}$ but not in rodents, is closely related to GPR41 and GPR43, but it is not activated by SCFA ${ }^{(4)}$.

SCFA are produced in the gut by bacterial fermentation of undigested carbohydrates. Concentrations of propionate and butyrate in peripheral and portal blood may, especially after feeding, be sufficient to activate GPR41 $1^{(4,5,7-11)}$. GPR41 couples to $G \alpha_{i}$, lowering the intracellular concentration of cyclic AMP. This may affect both energy balance and glucose homoeostasis, owing to the expression of GPR41 in various tissues $^{(4,5)}$. First, GPR41 is expressed in enteroendocrine cells $^{(12)}$ where it promotes the secretion of peptide YY $(\mathrm{PYY})^{(13)}$, which inhibits gastric emptying and food intake. As PYY is co-expressed with glucagon-like peptide 1 in enteroendocrine (L) cells ${ }^{(14)}$, activation of GPR41 might also increase the secretion of glucagon-like peptide 1, which like PYY inhibits gastric emptying and food intake, as well as stimulating insulin secretion from islet of Langerhans $\beta$-cells ${ }^{(15)}$. Consistent with this mechanism, it was reported recently that GPR41 knockout mice exhibit reduced glucagon-like peptide-1 secretion, both in vivo and from primary colonic cultures. Secretion of glucagon-like peptide-1 was not via a $G \alpha_{i}$-mediated pathway, however, which is not consistent with known signalling pathways for GPR41. Moreover, glucagon-like peptide-1 secretion is stimulated by elevation, not reduction, of the cyclic AMP concentration ${ }^{(16)}$. Second, GPR41 is expressed in the pancreas ${ }^{(4)}$, including human and mouse islets of Langerhans ${ }^{(17-19)}$, and in the insulin-secreting cell line MIN6 ${ }^{(18,20)}$. Direct activation of GPR41 in $\beta$-cells of the islets of Langerhans would be expected to inhibit insulin secretion $^{(17)}$, contrasting with any possible stimulatory effect mediated by glucagon-like peptide- 1 .

Third, some workers have reported that GPR41 mRNA is expressed in murine adipose tissue, where it mediates leptin secretion in response to $\mathrm{SCFA}^{(21)}$. However, we $\mathrm{w}^{(20)}$ and others $^{(22)}$ could not detect expression in murine

Abbreviations: GPCR/GPR, G-protein-coupled receptor; PYY, peptide YY.

*Corresponding author: J. R. S. Arch, fax +44 1280820135 , email jon.arch@buckingham.ac.uk

†Present address: Department of Cardiovascular Medicine, Wellcome Trust Centre for Human Genetics, Roosevelt Drive, Oxford OX3 7BN, UK. $\ddagger$ Present address: Department of Molecular Medicine, School of Medical Science, Kwame Nkrumah University of Science and Technology, Kumasi, Ghana. 
adipose tissue. Fourth, GPR41 is expressed in sympathetic ganglia where its activation by SCFA promotes sympathetic outflow ${ }^{(23)}$, which would be expected to promote resistance to obesity and improve insulin sensitivity.

Although it is difficult to predict from these reports how the absence of GPR41 would affect glucose homoeostasis, they are largely consistent in predicting that absence of GPR41 should promote obesity. Others have reported, however, that the absence of GPR41 promotes leanness, provided mice are raised conventionally and therefore have a gut microbiota that is able to produce SCFA. Absence of GPR 41 was associated with increased intestinal transit rate and reduced absorption of energy ${ }^{(13)}$. The aim of this work was, therefore, to reinvestigate energy balance in GPR 41 knockout mice and to determine how the various possible influences on glucose homoeostasis of an absence of GPR 41 balance out in the whole animal. We have compared male and female GPR41 knockout and wild-type mice fed on low- and high-fat diets, up to 40 weeks of age. By contrast with a previous report ${ }^{(13)}$, we find that male knockout mice have increased body fat mass, coupled with decreased energy expenditure, consistent with a role for GPR41 in the regulation of sympathetic outflow.

\section{Methods}

Housing and procedures were conducted in accordance with the UK Government Animal (Scientific procedures) Act 1986 and approved by the University of Buckingham Ethical Review Board.

\section{Mice and diet}

GPR41 knockout mice were generated by Deltagen, transferred via AstraZeneca to the University of Buckingham and bred, genotyped and further backcrossed to the C57Bl/ 6 strain, as described previously ${ }^{(20)}$. The mice used in the present experiments had been backcrossed to the $\mathrm{C} 57 \mathrm{Bl} / 6$ strain at least seven times.

Mice were housed in groups of three at $21 \pm 1^{\circ} \mathrm{C}$ with lights on from 07.00 to 19.00 hours. There were nine mice in each of eight groups, divided by genotype, sex and diet (wild-type or GPR41 knockout; male or female; low-fat or high-fat diet). They were given ad libitum access to tap water and all initially fed on a standard low-fat diet that provided, by energy content, 5\% fat, $75 \%$ carbohydrate and 20\% protein $(14.0 \mathrm{~kJ} / \mathrm{g}$ metabolisable energy; Rat and Mouse Diet 1, BK001E, Beekay Feed; B\&K Universal Limited). The high-fat diet-fed mice were fed on this diet until 15 weeks of age and then given a high-fat diet that provided, by energy content, $45 \%$ fat, $35 \%$ carbohydrate (of which half was sucrose) and $20 \%$ protein (D12451; Research Diets, Inc.). Further information on the composition of the diets is given in Table 1 . Food and water intake for each cage and individual body weights were measured weekly from 6 or 15 weeks of age in the low- or high-fat diet experiments, respectively. Mice were killed by cervical dislocation following $\mathrm{CO}_{2}$ anaesthesia when they were 40 weeks old, after being fasted for $5 \mathrm{~h}$ from 08.00 hours.
Table 1. Composition of diets*

\begin{tabular}{lcc}
\hline & Low-fat diet & High-fat diet \\
\hline Metabolisable energy (kJ/g) & 14.0 & $17 \cdot 0$ \\
Fat (\% of metabolisable energy) & 5 & $45 \dagger$ \\
$\%$ SFA & 21 & 36 \\
$\%$ MUFA & 25 & 45 \\
$\%$ PUFA & 54 & 19 \\
Carbohydrate (\% of metabolisable energy) & 75 & 35 \\
$\%$ Of carbohydrate as sugars & 10 & $50 \ddagger$ \\
Protein (\% of metabolisable energy) & 20 & 20 \\
Fibre (\% by weight) & 3.5 & 5.8 \\
\hline
\end{tabular}

*\% Fatty acids in fat and sugars in carbohydrate are by weight. † $88 \%$ as lard; $12 \%$ as soya bean oil.

$\ddagger$ As added sucrose.

\section{Glucose tolerance test}

Glucose tolerance was measured in all eight groups of mice when they were 27 weeks old. It was also measured in lowfat-fed mice when they were 10 weeks old. The mice were fasted for $5 \mathrm{~h}$ from 08.00 hours before administration of glucose ( $2 \mathrm{~g} / \mathrm{kg}$ body weight, intraperitoneally). Blood samples were taken from the tip of the tail at 30-min intervals after topical application of a local anaesthetic (lignocaine gel). Glucose and insulin were measured as previously described ${ }^{(24)}$. Total areas under the glucose tolerance curve were calculated for 120 min after administration of glucose using GraphPad Prism software (version 5; GraphPad Software, Inc.).

\section{Plasma and blood analytes}

Plasma and blood samples were taken from male and female mice after they had been fasted for $5 \mathrm{~h}$ from 08.00 hours, except as described earlier for glucose and insulin in the glucose tolerance test. Plasma adiponectin (Bridge International, Inc.), insulin and leptin (Crystal Chem, Inc.) were measured by mouse-specific ELISA. Blood glucose, cholesterol, TAG (Thermo Fisher Scientific), NEFA (Wako Chemicals) and HDL-cholesterol (Trinity Biotech) were measured by colorimetry.

\section{Energy expenditure}

Energy expenditure was measured by open-circuit indirect calorimetry, as previously described ${ }^{(25)}$, when the highfat diet-fed mice were 15, 27 and 40 weeks old. Energy expenditure of all the different genotypes in a group was measured in a single run over $24 \mathrm{~h}$ at room temperature $\left(21 \pm 1^{\circ} \mathrm{C}\right)$. The mice had free access to food. Energy expenditure was calculated by customised software using the equation of Weir ${ }^{(26)}$

\section{Body composition}

Body composition was determined using a dual-energy X-ray absorptiometry (Lunar Piximus densitometer; Lunar Corporation) scanner at 10, 22 and 40 weeks of age in the low-fat-fed mice and at 22, 27 and 40 weeks of age in the high-fat diet-fed mice. Mice were anaesthetised with 
isoflurane (1.5\%) during data acquisition. Body composition was calculated using the manufacturer's software (version 1.45).

\section{Liver TAG and glycogen content}

Left lobe liver samples were dissected and snap-frozen into liquid $\mathrm{N}_{2}$. Approximately, 150-300 mg of tissue were homogenised in $500 \mu \mathrm{l}$ methanol. Chloroform $(1 \mathrm{ml})$ was added and the samples vortexed and then incubated at $-20^{\circ} \mathrm{C}$ overnight. Saline $(200 \mu \mathrm{l})$ was added and the samples were centrifuged at $300 \mathrm{~g}$ for $5 \mathrm{~min}$. Chloroform was removed from an aliquot $(500 \mu \mathrm{l})$ of the chloroform phase using a RapidVap evaporation system (Cole-Parmer Instrument Company Limited). TAG was dissolved in ethanol $(200 \mu \mathrm{l})$ and assayed colorimetrically (TAG reagent; Thermo Fisher Scientific). Liver glycogen was determined by homogenising tissue in $\mathrm{KOH}$, precipitating glycogen using ethanol and treating it with amyloglucosidase before assaying glucose, as described previously ${ }^{(27)}$.

\section{Soleus muscle glucose uptake and palmitate oxidation}

2-Deoxy $\left[1-{ }^{14} \mathrm{C}\right]$ glucose uptake and $\left[1-{ }^{14} \mathrm{C}\right]$ palmitate oxidation by soleus muscle from low-fat-fed 20-week-old mice were measured as previously described ${ }^{(28)}$.

\section{Locomotor activity}

Mice were placed individually in a rectangular cage $(42 \times 25 \mathrm{~cm})$ in which the bottom of the cage was divided by black lines into six equal rectangles. Following a habituation day, video camera shots were taken every $3 \mathrm{~s}$ for $16 \mathrm{~min}$, beginning at $45 \mathrm{~min}$ before and $15 \mathrm{~min}$ after the dark period. Horizontal locomotor activity was assessed by two independent observers, in a similar manner to that described by others ${ }^{(29)}$, from the number of times the mouse moved to a different square between shots. The observers did not know the genotype or the diet of the mice.

\section{RNA isolation and real-time quantitative $P C R$ analysis of} gene expression

Total RNA was isolated and complementary DNA synthesised as described previously ${ }^{(20)}$. Quantitative PCR was performed using Assay on Demand pre-designed primer and probe sets from Applied Biosystems. Transcript levels were quantified in triplicate by real-time RT-PCR and normalisation to housekeeping genes (tubulin, cyclophilin, hypoxanthine phosphoribosyltransferase and $\beta$-glucouronidase using geNorm software; Primer Design Limited), as described previously ${ }^{(20)}$.

\section{Statistical analysis}

Data were analysed using one- or two-way with repeated measures ANOVA, as appropriate, using GraphPad Prism software (version 5). If the ANOVA showed significant effects of genotype, comparisons were made between the wild-type and knockout mice of the same sex at specific time points using Fisher's least significant difference test. Two-sided

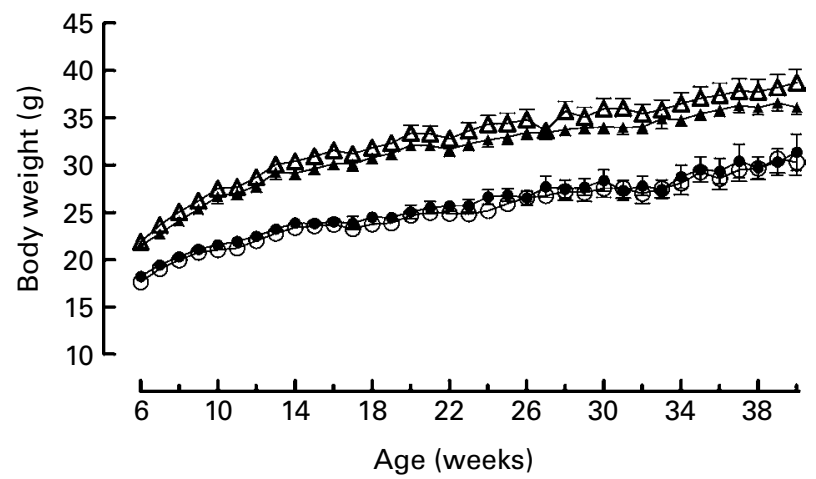

Fig. 1. Growth curves for wild-type ( $\bullet$ and $\mathbf{\Delta})$ and G-protein-coupled receptor 41 knockout $(\bigcirc$ and $\triangle$ ) male $(\triangle$ and $\Delta)$ and female $(\bigcirc$ and $\bullet$ ) mice $(n 9)$. Two-way repeated-measures ANOVA did not show a significant effect of genotype on body weight in either male or female mice.

significance levels are given. Differences were considered significant at $P<0 \cdot 05$. Results are shown as mean values with their standard errors.

\section{Results}

\section{Low-fat-fed mice}

Genotype had no statistically significant effect on the growth curves of either the male or the female mice (Fig. 1). Genotype also had no effect on food intake (males: wild-type 844 (SEM 64), knockout 857 (SEM 59); females: wild-type 821 (SEM 13), knockout 770 (SEM 25) g/mouse per 40 weeks). Body fat mass was affected by genotype in the male knockout mice, being higher in the knockout than the wild-type mice at 40 weeks of age. Body lean mass was not affected by genotype in the male mice (Table 2). Genotype did not significantly affect the plasma leptin concentration in the male mice ( $P=0.057$ by two-way repeated measures ANOVA), but plasma adiponectin was elevated at both 22 and 40 weeks of age (Table 3). There was no effect of genotype on body composition or plasma leptin or adiponectin concentration in the female mice (Tables 2 and 3).

At termination ( 40 weeks of age), there was no difference between genotypes in absolute liver weights, but liver weight relative to body weight was reduced in the male knockout mice, because the mean body weight was higher (but not significantly so) than in the wild-type mice (Table 4). The TAG content of the livers of the male knockout mice was markedly reduced (Table 4), possibly because the plasma NEFA concentration, a source of liver TAG, was reduced (Table 3). Genotype affected neither the liver TAG nor the plasma NEFA concentration of the female mice (Tables 3 and 4). Genotype did not affect plasma TAG, total cholesterol or HDL concentration in either sex at any age (Table 3). Soleus muscle and heart weights were lower in the knockout than in the wild-type mice when measured in a separate group of male mice (Table 4), but genotype did not affect palmitate oxidation or glucose uptake relative to tissue weight by soleus muscle (Fig. S1, available online).

The fasting blood glucose concentration (at both -30 and $0 \mathrm{~min}$ ) was not affected by genotype in either sex,

\footnotetext{
using Fisher's least significant difference test. Two-sided
} 
Table 2. Body composition of low-fat-fed mice†

(Mean values with their standard errors)

\begin{tabular}{|c|c|c|c|c|c|c|c|c|c|}
\hline \multirow[b]{3}{*}{ Sex } & \multirow[b]{3}{*}{ Age (weeks) } & \multicolumn{4}{|c|}{ Fat $(\mathrm{g})$} & \multicolumn{4}{|c|}{ Lean (g) } \\
\hline & & \multicolumn{2}{|c|}{ Wild-type } & \multicolumn{2}{|c|}{ Knockout } & \multicolumn{2}{|c|}{ Wild-type } & \multicolumn{2}{|c|}{ Knockout } \\
\hline & & Mean & SEM & Mean & SEM & Mean & SEM & Mean & SEM \\
\hline \multirow[t]{3}{*}{ Male } & 10 & 3.41 & 0.11 & 3.41 & 0.14 & 23.56 & 0.65 & $22 \cdot 82$ & 0.57 \\
\hline & 22 & 4.58 & 0.51 & 6.64 & 0.79 & $25 \cdot 68$ & 0.70 & $25 \cdot 36$ & 0.73 \\
\hline & 40 & 7.01 & 0.78 & $10 \cdot 89^{\text {***}}$ & 1.28 & $26 \cdot 14$ & 1.02 & $26 \cdot 76$ & 0.78 \\
\hline \multirow{3}{*}{ Female } & 10 & $3 \cdot 10$ & 0.14 & 3.06 & 0.10 & $18 \cdot 60$ & 0.40 & $18 \cdot 42$ & 0.26 \\
\hline & 22 & 3.96 & 0.27 & 4.56 & 0.33 & 21.06 & 0.61 & $19 \cdot 98$ & 0.39 \\
\hline & 40 & 7.93 & $1 \cdot 17$ & 9.59 & 1.17 & $22 \cdot 10$ & 0.57 & 21.41 & 0.33 \\
\hline
\end{tabular}

${ }^{\star * \star}$ Mean values was significantly different from that of the wild-type mice $(P<0.001)$.

†Two-way repeated-measures ANOVA showed a significant $(P<0.01)$ effect of genotype on body fat content in the male mice.

but intraperitoneal glucose tolerance was impaired in 27-week-old male but not female knockout mice (Fig. 2). It was not impaired in 10-week-old male knockout mice - an age when they did not have a raised body fat content (AUC: wild-type 1382 (SEM 158); knockout 1338 (sEm 123) $\mathrm{mm} \times 120 \mathrm{~min})$. Genotype did not affect the plasma insulin concentration in either male or female mice $30 \mathrm{~min}$ before or after administration of glucose (Fig. 2(c) and (f)).

\section{High-fat diet-fed mice}

Mice were fed on a high-fat diet from 15 weeks of age. The growth curves of the knockout and wild-type mice were similar (Fig 3). Genotype did not affect the food intake of either sex (males: wild-type 336 (sEm 16), knockout 300 (sem 36); females: wild-type 243 (sem 12), knockout 248 (SEm 248) g/mouse per 15 weeks). Although the body weight of the male mice was unaffected by genotype, body fat mass and plasma leptin concentration were affected by genotype in male mice, being higher in 27-week-old male knockout than in the wild-type mice (Tables 5 and 6). Body lean mass, by contrast, was decreased at 22, 27 and 40 weeks of age (Table 5). Genotype did not affect the body composition of the female mice (Table 5). Genotype did not affect liver weight in either sex in mice fed on the high-fat diet, nor did it affect plasma NEFA or lipids (Tables 4 and 6).

The fasting blood glucose concentration (at both -30 and $0 \mathrm{~min}$ ) and glucose tolerance were not affected by genotype in either the male or female mice (Fig. 4), but the plasma insulin concentration $30 \mathrm{~min}$ after the glucose load was higher in the knockout than the wild-type mice of both sexes (Fig. 4).

\section{Energy expenditure and muscle metabolism}

Energy expenditure was measured over $24 \mathrm{~h}$ in the high-fatfed mice in their home cages in an attempt to understand why the males became obese without their having a detectable increase in energy intake. Energy expenditure was lower in the male knockout than in the male wild-type mice throughout the $24 \mathrm{~h}$ measurement period (Fig. 5). It was not low in the female knockout mice, consistent with only the male knockout mice becoming obese.

Observation of individually housed male mice, aged 35-39 weeks, for $15 \mathrm{~min}$ during the light and dark periods showed that low energy expenditure in knockout mice was not due to reduced horizontal locomotor activity (Table S1, available online).

Table 3. Plasma hormone and metabolite concentrations in low-fat-fed mice $\dagger$ (Mean values with their standard errors, $n$ 9)

\begin{tabular}{|c|c|c|c|c|c|c|c|c|c|}
\hline \multirow[b]{3}{*}{ Analyte } & \multirow[b]{3}{*}{ Age (weeks) } & \multicolumn{4}{|c|}{ Males } & \multicolumn{4}{|c|}{ Females } \\
\hline & & \multicolumn{2}{|c|}{ Wild-type } & \multicolumn{2}{|c|}{ Knockout } & \multicolumn{2}{|c|}{ Wild-type } & \multicolumn{2}{|c|}{ Knockout } \\
\hline & & Mean & SEM & Mean & SEM & Mean & SEM & Mean & SEM \\
\hline \multirow[t]{2}{*}{ Leptin (ng/ml) } & 22 & $12 \cdot 8$ & 3.4 & $19 \cdot 8$ & 4.5 & $7 \cdot 8$ & $2 \cdot 2$ & $9 \cdot 0$ & $2 \cdot 6$ \\
\hline & 40 & $18 \cdot 8$ & $5 \cdot 1$ & 31.3 & $5 \cdot 7$ & $17 \cdot 9$ & 3.4 & $22 \cdot 1$ & $5 \cdot 0$ \\
\hline \multirow[t]{2}{*}{ Adiponectin $(\mu \mathrm{g} / \mathrm{ml})$} & 22 & $7 \cdot 1$ & 0.5 & $11 \cdot 8^{\star \star \star}$ & 0.8 & $15 \cdot 7$ & 0.4 & $13 \cdot 7$ & 0.6 \\
\hline & 40 & $7 \cdot 6$ & $0 \cdot 6$ & $10 \cdot 4^{*}$ & $0 \cdot 8$ & $13 \cdot 7$ & $1 \cdot 8$ & $13 \cdot 7$ & 0.9 \\
\hline \multirow{2}{*}{ NEFA (mм) } & 22 & 1.52 & $0 \cdot 10$ & $1 \cdot 19^{\star}$ & $0 \cdot 12$ & 1.01 & 0.07 & 1.06 & $0 \cdot 18$ \\
\hline & 40 & 1.61 & 0.11 & $1 \cdot 17^{\star *}$ & $0 \cdot 10$ & 1.73 & $0 \cdot 11$ & 1.77 & 0.17 \\
\hline TAG (mM) & 40 & 0.83 & 0.09 & 0.64 & 0.08 & 0.69 & 0.08 & 0.79 & 0.08 \\
\hline Total cholesterol (mM) & 40 & $2 \cdot 28$ & 0.17 & $2 \cdot 31$ & 0.12 & 1.74 & $0 \cdot 10$ & 2.00 & 0.07 \\
\hline HDL-cholesterol (mM) & 40 & 0.97 & 0.05 & 1.00 & 0.07 & 0.71 & 0.14 & 0.88 & 0.04 \\
\hline
\end{tabular}

Mean values was significantly different from that of the wild-type mice: ${ }^{\star} P<0.05,{ }^{\star \star} P<0.01,{ }^{\star \star \star} P<0.001$.

†Two-way repeated-measures ANOVA did not show a significant effect of genotype on plasma leptin $(P=0.057$ in males), but in male mice there were significant effects of genotype on plasma adiponectin $(P<0.001)$ and NEFA $(P<0.01)$. 
Table 4. Liver composition and tissue weights $\dagger$

(Mean values with their standard errors, $n 8$ or 9 )

\begin{tabular}{|c|c|c|c|c|c|c|c|c|}
\hline & \multicolumn{4}{|c|}{ Males } & \multicolumn{4}{|c|}{ Females } \\
\hline & \multicolumn{2}{|c|}{ Wild-type } & \multicolumn{2}{|c|}{ Knockout } & \multicolumn{2}{|c|}{ Wild-type } & \multicolumn{2}{|c|}{ Knockout } \\
\hline & Mean & SEM & Mean & SEM & Mean & SEM & Mean & SEM \\
\hline \multicolumn{9}{|l|}{ Low-fat diet } \\
\hline Liver weight (g) & 1.74 & 0.07 & 1.65 & 0.06 & $1 \cdot 3$ & 0.04 & $1 \cdot 29$ & 0.05 \\
\hline Relative liver weight (\%) & 4.91 & 0.20 & $4 \cdot 31^{*}$ & $0 \cdot 11$ & $4 \cdot 31$ & 0.22 & $4 \cdot 33$ & 0.14 \\
\hline Liver TAG ( $\mu \mathrm{mol} / \mathrm{g}$ tissue) & 7.9 & 1.5 & $2 \cdot 3^{\star \star \star}$ & 0.9 & $14 \cdot 22$ & $2 \cdot 1$ & $15 \cdot 2$ & $2 \cdot 4$ \\
\hline Liver glycogen ( $\mu \mathrm{mol} / \mathrm{g}$ tissue) & 154 & 10 & 156 & 7 & 91 & 31 & 264 & 20 \\
\hline Soleus weight (mg) & 9.5 & 0.3 & $8.5^{\star}$ & 0.2 & - & - & - & - \\
\hline Heart weight (mg) & 171 & 10 & $139^{*}$ & 5 & - & - & - & - \\
\hline \multicolumn{9}{|l|}{ High-fat diet } \\
\hline Liver weight (g) & 1.58 & 0.18 & $1 \cdot 78$ & 0.28 & 1.07 & 0.06 & $1 \cdot 17$ & 0.04 \\
\hline Relative liver weight (\%) & 3.59 & 0.32 & $4 \cdot 15$ & 0.58 & $2 \cdot 98$ & $0 \cdot 18$ & 3.25 & 0.18 \\
\hline
\end{tabular}

\section{Gene expression}

There were no effects of genotype in male, 10- to 12-week old, low-fat-fed mice on levels of mRNA in liver, muscle, epididymal white adipose tissue or interscapular brown adipose tissue for GPR40, GPR120, PPAR $\gamma$ coactivator-1 $\alpha$ sarco (endo)plasmic reticulum $\mathrm{Ca}^{2+}$ ATPase 1 , type 2 deiodinase or carnitine palmitoyl transferase-1a; in liver only for sterol regulatory element-binding protein-1c, fatty acid synthetase or acetyl CoA carboxylase-1; or in brown adipose tissue for

(a)

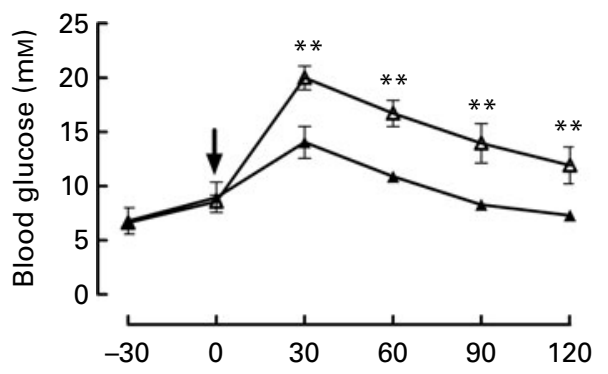

(d)

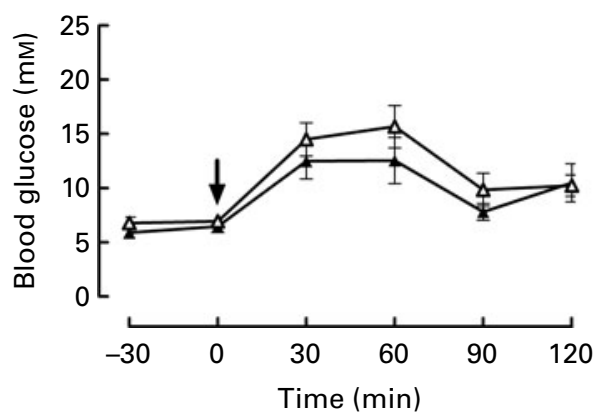

the $\beta_{3}$-adrenoceptor (data not shown). We have reported elsewhere $^{(20)}$ a reduction in the expression of GPR43 in white adipose tissue of GPR41 knockout mice.

\section{Discussion}

Most reports on the expression and function of GPR41 in murine tissues lead to the prediction that its absence should promote obesity. Evidence has been presented, however, (b)

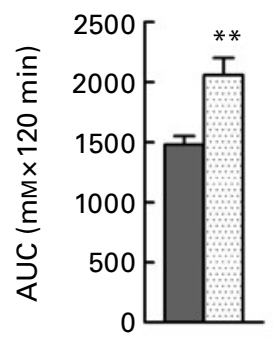

(e)

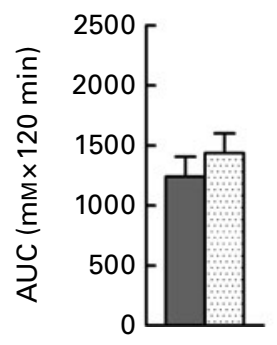

(c)

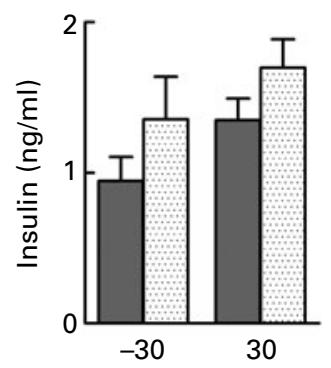

(f)

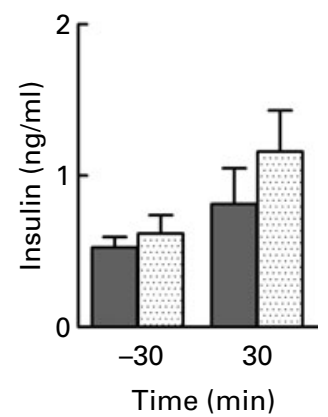

Fig. 2. (a, d) Glucose tolerance, (b, e) area under the glucose tolerance curve and (c, f) plasma insulin before and after administration of glucose in 27-week-old male $(\mathrm{a}-\mathrm{c})$ and female $(\mathrm{d}-\mathrm{f})$ mice fed on a low-fat diet. Wild-type mice are shown with $\mathbf{\square}$ or $\boldsymbol{\Delta}$, and knockout mice with $\therefore$ or $\Delta(n 6)$. Values are means, with standard errors represented by vertical bars. Two-way, repeated-measures ANOVA showed a significant $(P<0.01)$ effect of genotype on blood glucose in the male mice. ${ }^{* \star}$ Mean value was significantly different from that of the wild-type mice $(P<0.001)$. 


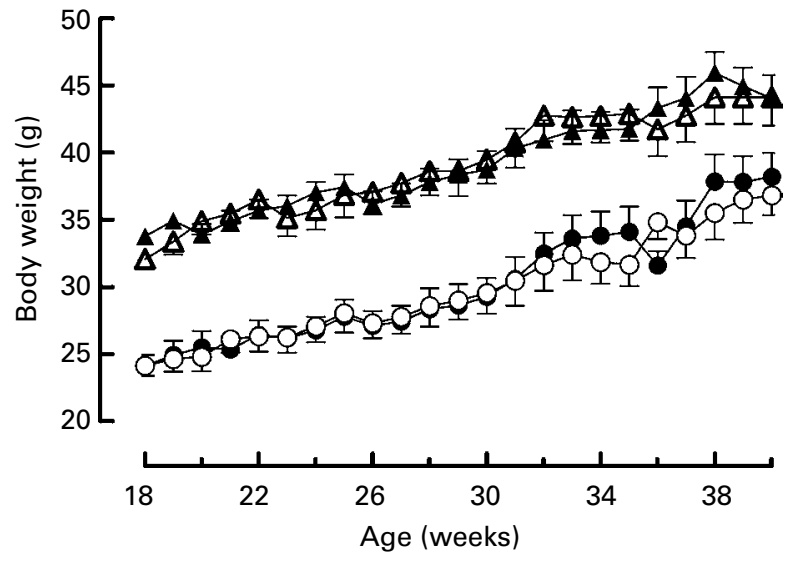

Fig. 3. Growth curves for wild-type ( $\bullet$ and $\mathbf{\Delta})$ and G-protein-coupled receptor 41 knockout $(\bigcirc$ and $\triangle$ ) male $(\triangle$ and $\Delta)$ and female $(\bigcirc$ and $\bullet$ ) mice $(n 9)$. Two-way repeated-measures ANOVA did not show a significant effect of genotype on body weight in either male or female mice.

that its absence is associated with leanness, owing to increased intestinal transit rate and reduced absorption of energy $^{(13)}$. We found, by contrast, that absence of GPR41 was associated with increased body fat content in male mice fed on either a low-fat or a high-fat diet, including when the mice were of the same age ( 10 weeks) as those used in the previous report. Nevertheless, we do not rule out the possibility that increased intestinal transit rate and reduced absorption of energy might have mitigated obesity in the GPR41 knockout mice used in the present study.

The male GPR41 knockout mice used in the present study also displayed impaired glucose tolerance, elevated plasma adiponectin and lowered plasma NEFA and liver TAG concentrations when fed on a low-fat diet. They displayed reduced lean body mass, elevated plasma leptin and elevated plasma insulin following administration of glucose when fed on a high-fat diet. The only effect of an absence of GPR41 in the female mice was an increase in the concentration of insulin after administration of glucose in the high-fat-fed mice.

A surprising finding was that the phenotype of the male GPR41 knockout mice was not exacerbated by feeding on a high-fat diet. Indeed, body fat content was elevated in 27-week-old but not in 40-week-old high-fat-fed knockout mice. Usually, a high-fat diet exacerbates the metabolic phenotype of GM mice. It is feasible that replacement of carbohydrate with fat in the high-fat diet reduced the production of SCFA in the gut and thereby the exposure of GPR41 to SCFA.

It has been claimed that the GPR41 gene is expressed in murine adipose tissue, where it mediates the stimulation of leptin secretion by SCFA ${ }^{(21)}$. However, it is unlikely that the increased body fat content of male GPR41 knockout mice was primarily due to the regulation of leptin secretion by GPR41. We ${ }^{(20)}$ and others ${ }^{(22)}$ have been unable to detect GPR41 mRNA in murine adipose tissue. Moreover, the plasma leptin concentration was increased rather than decreased in the male GPR41 knockout, high-fat-fed mice compared to wild-type mice. A similar trend $(P=0.057)$ was observed in male GPR41 knockout mice fed on the low-fat diet. Obesity in rodents is normally associated with elevated plasma leptin, because, with the exception of the Lep ${ }^{o b}$, $L e p^{o b}$ mouse, increased adipocyte number and, especially, adipocyte size are associated with increased leptin secretion.

Activation of GPR41 stimulates the secretion of PYY from L cells ${ }^{(12,13)}$, which would tend to decrease food intake. Others have suggested that propionate might enhance satiety by activating either GPR41 or GPR $43^{(30)}$. However, we could not detect increased food intake in GPR41 knockout mice. It is therefore unlikely that decreased secretion of PYY from enteroendocrine $\mathrm{L}$ cells played an important role in the obese phenotype of GPR41 knockout mice.

The feature of the GPR41 knockout mice that seems most likely to link to an increased body fat mass is reduced energy expenditure. The male, but not the female, highfat-fed knockout mice became obese and only the males exhibited low energy expenditure. A possible explanation for the reduced energy expenditure is suggested by a recent report that SCFA promote sympathetic outflow by activating GPR41 ${ }^{(23)}$. The mice used for that work were males (Professor Gozoh Tsujimoto, personal communication). It does not follow, however, that SCFA must fail to promote sympathetic outflow in female mice, because, as discussed later, female mice are often less susceptible than males to other genetic

Table 5. Body composition in high-fat-fed mice $\dagger$

(Mean values with their standard errors)

\begin{tabular}{|c|c|c|c|c|c|c|c|c|c|}
\hline \multirow[b]{3}{*}{ Sex } & \multirow[b]{3}{*}{ Age (weeks) } & \multicolumn{4}{|c|}{ Fat $(\mathrm{g})$} & \multicolumn{4}{|c|}{ Lean $(\mathrm{g})$} \\
\hline & & \multicolumn{2}{|c|}{ Wild-type } & \multicolumn{2}{|c|}{ Knockout } & \multicolumn{2}{|c|}{ Wild-type } & \multicolumn{2}{|c|}{ Knockout } \\
\hline & & Mean & SEM & Mean & SEM & Mean & SEM & Mean & SEM \\
\hline \multirow[t]{3}{*}{ Male } & 22 & 7.03 & 0.66 & $9.65^{*}$ & 0.92 & $25 \cdot 77$ & 0.71 & $22 \cdot 78^{*}$ & 0.79 \\
\hline & 27 & 8.32 & 1.46 & $12 \cdot 75^{\star}$ & $1 \cdot 10$ & $27 \cdot 70$ & 0.64 & $25 \cdot 15^{\star}$ & 0.98 \\
\hline & 40 & 15.43 & $1 \cdot 21$ & 17.05 & 1.62 & $29 \cdot 22$ & 0.55 & $26 \cdot 21^{*}$ & 0.99 \\
\hline \multirow[t]{3}{*}{ Female } & 22 & $5 \cdot 79$ & 0.61 & $6 \cdot 13$ & 0.70 & $18 \cdot 68$ & 0.51 & 19.57 & 0.44 \\
\hline & 27 & 8.38 & 1.42 & 7.62 & $1 \cdot 18$ & 18.99 & 0.42 & 19.05 & 0.57 \\
\hline & 40 & $18 \cdot 22$ & $1 \cdot 70$ & $15 \cdot 88$ & 1.46 & $20 \cdot 41$ & 0.38 & $20 \cdot 60$ & 0.42 \\
\hline
\end{tabular}

${ }^{*}$ Mean value was significantly different from that of the wild-type mice $(P<0.05)$.

† Two-way repeated-measures ANOVA showed significant effects of genotype on body fat $(P<0.05)$ and body lean content $(P<0.01)$ in the male mice. 
Table 6. Plasma hormone and metabolite concentrations in high-fat-fed mice†

(Mean values with their standard errors)

\begin{tabular}{|c|c|c|c|c|c|c|c|c|c|}
\hline \multirow[b]{3}{*}{ Analyte } & \multirow[b]{3}{*}{ Age (weeks) } & \multicolumn{4}{|c|}{ Males } & \multicolumn{4}{|c|}{ Females } \\
\hline & & \multicolumn{2}{|c|}{ Wild-type } & \multicolumn{2}{|c|}{ Knockout } & \multicolumn{2}{|c|}{ Wild-type } & \multicolumn{2}{|c|}{ Knockout } \\
\hline & & Mean & SEM & Mean & SEM & Mean & SEM & Mean & SEM \\
\hline \multirow[t]{3}{*}{ Leptin (ng/ml) } & 22 & $11 \cdot 7$ & $5 \cdot 2$ & $23 \cdot 6$ & $4 \cdot 1$ & $12 \cdot 6$ & $2 \cdot 2$ & 9.2 & $2 \cdot 6$ \\
\hline & 27 & $15 \cdot 7$ & 5.5 & $34 \cdot 9^{\star \star}$ & $5 \cdot 3$ & $23 \cdot 0$ & $3 \cdot 3$ & $17 \cdot 6$ & $2 \cdot 5$ \\
\hline & 40 & $32 \cdot 6$ & 5.0 & 42.5 & 6.9 & 53.2 & $6 \cdot 3$ & $40 \cdot 7$ & $8 \cdot 2$ \\
\hline \multirow[t]{3}{*}{ Adiponectin $(\mu \mathrm{g} / \mathrm{ml})$} & 22 & $10 \cdot 1$ & 0.9 & $11 \cdot 0$ & 0.9 & $18 \cdot 8$ & $1 \cdot 1$ & $17 \cdot 8$ & 1.3 \\
\hline & 27 & $9 \cdot 1$ & $1 \cdot 2$ & $10 \cdot 2$ & 0.8 & $18 \cdot 4$ & 0.6 & $14 \cdot 1$ & 1.3 \\
\hline & 40 & 8.2 & 0.8 & 8.3 & 0.5 & $15 \cdot 7$ & 0.8 & $13 \cdot 8$ & 0.3 \\
\hline \multirow[t]{2}{*}{ NEFA (mм) } & 27 & 1.05 & 0.18 & 0.75 & 0.09 & 0.66 & 0.03 & 0.70 & 0.09 \\
\hline & 40 & 1.55 & 0.06 & 1.38 & 0.12 & 1.56 & 0.11 & 1.53 & 0.24 \\
\hline TAG (mM) & 40 & 0.65 & 0.06 & 0.58 & 0.06 & 0.56 & 0.03 & 0.60 & 0.04 \\
\hline Total cholesterol (mM) & 40 & 4.45 & 0.81 & 4.97 & 0.34 & 3.40 & 0.27 & 3.88 & 0.28 \\
\hline HDL-cholesterol (mM) & 40 & 1.56 & 0.23 & 1.62 & 0.11 & 1.31 & 0.10 & 1.52 & 0.11 \\
\hline
\end{tabular}

** Mean value was significantly different from that of the wild-type mice $(P<0.01)$

†Two-way repeated-measures ANOVA showed a significant effect of genotype on plasma leptin $(P<0.05)$ in the male mice.

modifications that cause obesity in males. Female mice and rats are also less susceptible than males to high-fat dietinduced obesity and diabetes.

Another possible explanation for the reduced energy expenditure of the male knockout mice, particularly those fed on the high-fat diet, is that they have a reduced mass of energy consuming tissues. Total lean body mass was reduced in the male but not the female mice fed on a high-fat diet compared to wild-type mice. Lean body mass is associated with greater whole-body energy expenditure than is fat mass $^{(31,32)}$. Total lean body mass did not differ between knockout and wild-type male mice fed on the low-fat diet, but soleus muscle and heart weights were low in knockout mice. Therefore, the absence of GPR41 may inhibit the development of some energy consuming tissues, particularly red muscle.

A number of other possible explanations for this reduced energy expenditure can be discounted. It was not associated with reduced horizontal locomotor activity, consistent with it occurring throughout $24 \mathrm{~h}$ even though locomotor activity is greatest during the dark period. We could not detect any alteration in gene expression that might indicate decreased
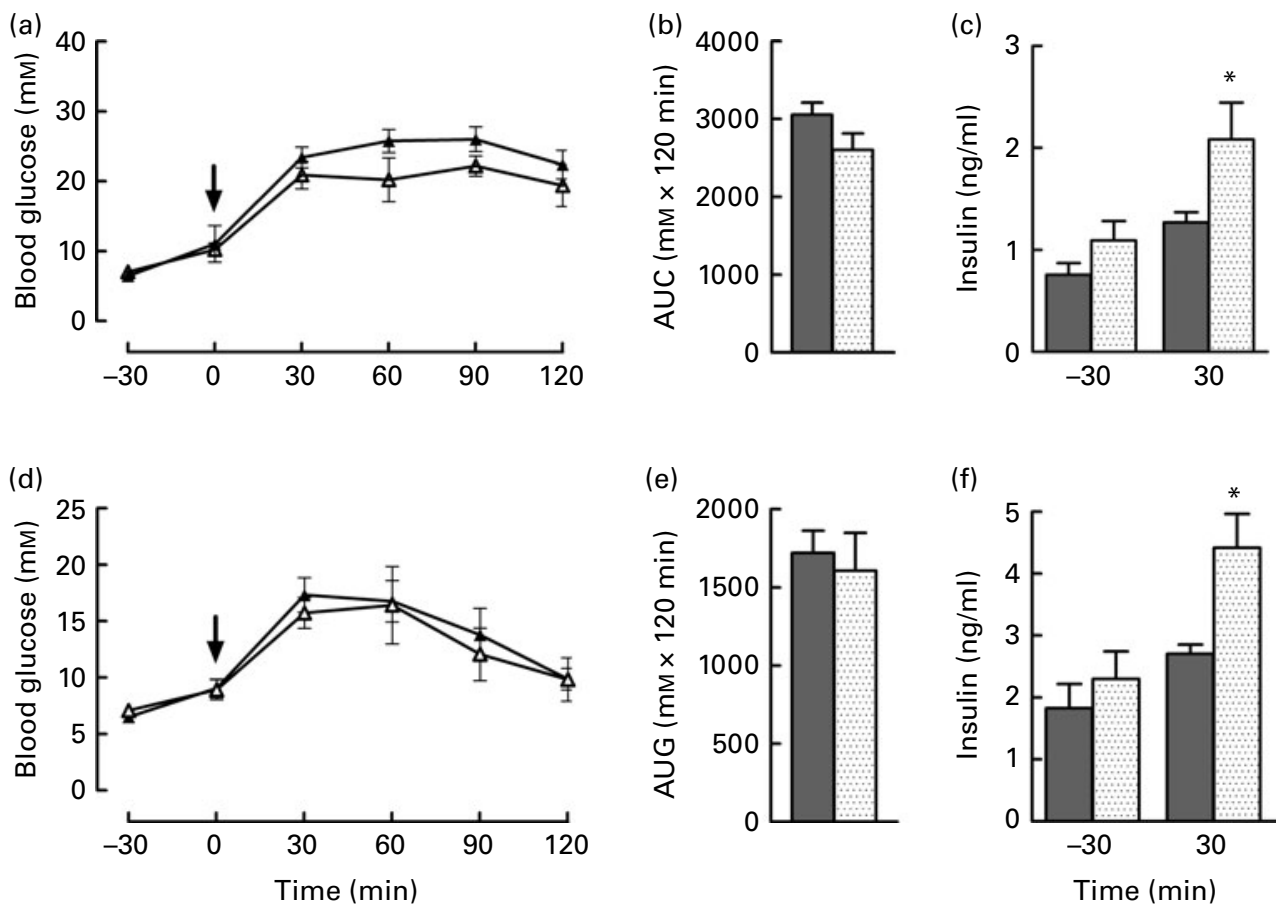

Fig. 4. (a, d) Glucose tolerance, (b, e) area under the glucose tolerance curve and (c, f) plasma insulin before and after administration of glucose in 27 -week-old male $(a-c)$ and female $(d-f)$ mice fed on a high-fat diet. Wild-type mice are shown with $\mathbf{\square}$ or $\boldsymbol{\Delta}$ and knockout mice with $\therefore$ or $\Delta$. ( $n 6)$. Values are means, with standard errors represented by vertical bars. Two-way, repeated measures ANOVA showed significant $(P<0.05)$ effects of genotype on plasma insulin in both male and female mice. *Mean value was significantly different from that of the wild-type mice $(P<0.05)$. 

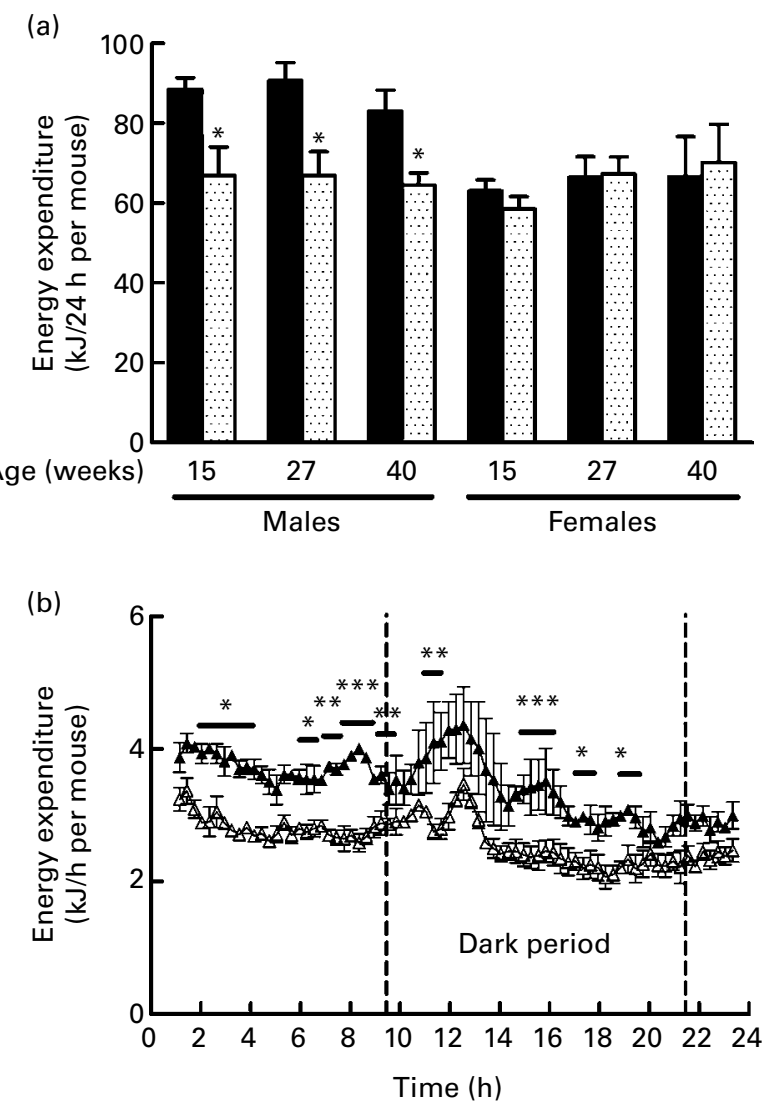

Fig. 5. Energy expenditure in mice fed on a high-fat diet. (a) Daily energy expenditure in wild-type ( $\square$ ) and G-protein-coupled receptor 41 (GPR41) ([.) knockout mice. (b) Hourly energy expenditure in 40-week-old male wild-type $(\Delta)$ and GPR41 $(\triangle)$ knockout mice. Values are means, with standard errors represented by vertical bars. Two-way, repeated-measures ANOVA showed significant effects of genotype $(P<0.05)$ on both 24 -h and hourly energy expenditure. Mean value of the knockout mice was significantly different from that of the wild-type mice: ${ }^{\star} P<0.05,{ }^{\star \star} P<0.01,{ }^{\star \star \star} P<0.001$.

fuel metabolism in muscle, liver or brown adipose tissue, and fatty acid oxidation and glucose uptake per g soleus muscle weight did not differ between genotypes. Plasma adiponectin concentration, which might be expected to be associated with increased fatty acid oxidation and weight loss ${ }^{(33,34)}$, was actually elevated in low-fat-fed male knockout mice, despite their increased body fat mass. The plasma adiponectin concentration is often inversely correlated with body fat mass ${ }^{(35)}$, but we and others have previously reported positive associations between body fat mass and plasma adiponectin concentration $^{(24,36-38)}$

There are numerous reports of sex differences in the effects of diet or genetic manipulation on body composition and metabolism in rodents, and it is often the males that show the greater changes ${ }^{(39-43)}$. The differing effects of male and female sex hormones on adipose tissue distribution and the central regulation of metabolism may be of general importance $^{(44,45)}$, but mechanisms specific to particular genetic or behavioural manipulations have also been proposed ${ }^{(40,43,46)}$. In the context of the present work, where obesity is linked to low energy expenditure, it may be relevant that female rats have greater oxidative capacity than male rats. This has been linked to differences in oxidative capacity between the sexes in liver, skeletal muscle and brown adipose tissue ${ }^{(47-49)}$. This may be because male and female sex hormones have opposite effects on the balance of $\alpha_{2 A^{-}}$and $\beta$-adrenoceptor expression in murine brown adipocytes ${ }^{(50)}$. However, as we were unable to identify any differences in gene expression in male mice that might underlie the differences in energy expenditure, we could not investigate whether any differences were absent in female mice.

Obesity is usually associated with insulin resistance. This may partly explain why the male knockout mice fed on the low-fat diet displayed an impaired glucose tolerance. The male knockout mice fed on the high-fat diet, by contrast, did not display impaired glucose tolerance. This may be because their plasma insulin concentration was higher following administration of glucose than in the wild-type mice. Moreover, the plasma insulin concentration following administration of glucose was higher in the female knockout mice fed on the high-fat diet than in the wild-type mice, even though their body fat content was no different from that of the wild-type mice. Stimulation of GPR 41 in $\beta$-cells of the islets of Langerhans would be expected to decrease insulin secretion because GPR 41 is coupled to $G \alpha_{i}$. These results, therefore, raise the possibility that the absence of GPR 41 in $\beta$-cells of high-fat diet-fed mice tends to promote insulin secretion in response to glucose.

Liver composition was studied in the low-fat-fed mice to investigate why liver weight relative to body weight was lower in male knockout compared to wild-type mice. The male low-fat-fed knockout mice had a lower liver TAG content, associated with lower plasma NEFA concentration, than the wild-type mice. The low liver TAG content in the livers of the male knockout mice can account, however, for only about $5 \mathrm{mg}$ of the $90 \mathrm{mg}$ (non-significant) difference in mean liver weight and so cannot explain the difference in relative liver weights. We do not have an explanation for the low liver TAG content and plasma NEFA concentration of the male knockout mice, but we suggest that they are linked. Interestingly, knockout of the GPR43 gene, another SCFA receptor, was also associated with reduced liver weight and TAG content, but only when mice were fed on a highfat diet ${ }^{(51)}$. Another difference from the present study is that GPR43 knockout mice were leaner than wild-type mice. As in the present study, the reduced liver weight could not be explained by the reduced liver TAG content.

In conclusion, in contrast to a previous report ${ }^{(13)}$, we find that male but not female GPR41 knockout mice have a higher body fat mass than their wild-type littermates, when they are fed on either a low- or a high-fat diet. This appears as a consequence of their energy expenditure being low. These results raise the possibility that gut-derived SCFA may raise energy expenditure by activating GPR41.

\section{Supplementary material}

To view supplementary material for this article, please visit http://dx.doi.org/10.1017/S0007114512003923 


\section{Acknowledgements}

The authors are highly appreciative of the staff in AstraZeneca, Animal Science and Welfare, for their invaluable work in animal husbandry, embryo rederivation, breeding and data generation. They thank Alison Davies at AstraZeneca Alderley Park for assistance with the analysis of gene expression, Anita Roberts and Miriam Fernander at Buckingham University for technical assistance and Paul Trayhurn for commenting on the manuscript. J. R. S. A., D. M. S., M. A. C., C. J. S. and M. B. designed the research. M. B. conducted most experiments with support from, and additional experiments conducted by, C. J. S., J. F. O., E. T. W., M. S. Z., D. C. H. and R. A. N. The data were analysed by M. B., J. R. S. A. and R. A. N. The first draft of the manuscript was written by M. B., and then rewritten and revised by J. R. S. A., with input from D. M. S., M. A. C. and C. J. S. This work was supported by funding from AstraZeneca. D. M. S. is an employee of AstraZeneca.

\section{References}

1. Hirasawa A, Hara T, Katsuma S, et al. (2008) Free fatty acid receptors and drug discovery. Biol Pharm Bull 31, 1847-1851.

2. Swaminath G (2008) Fatty acid binding receptors and their physiological role in type 2 diabetes. Arch Pharm 341, 753-761.

3. Wellendorph P, Johansen LD \& Brauner-Osborne H (2009) Molecular pharmacology of promiscuous seven transmembrane receptors sensing organic nutrients. Mol Pharmacol 76, 453-465.

4. Brown AJ, Goldsworthy SM, Barnes AA, et al. (2003) The Orphan G protein-coupled receptors GPR41 and GPR43 are activated by propionate and other short chain carboxylic acids. J Biol Chem 278, 11312-11319.

5. Le Poul E, Loison C, Struyf S, et al. (2003) Functional characterization of human receptors for short chain fatty acids and their role in polymorphonuclear cell activation. $\mathrm{J} \mathrm{Biol} \mathrm{Chem}$ 278, 25481-25489.

6. Liaw CW \& Connolly DT (2009) Sequence polymorphisms provide a common consensus sequence for GPR41 and GPR42. DNA Cell Biol 28, 555-560.

7. Cummings JH, Pomare EW, Branch WJ, et al. (1987) Short chain fatty acids in human large intestine, portal, hepatic and venous blood. Gut 28, 1221-1227.

8. Dankert J, Zijlstra JB \& Wolthers BG (1981) Volatile fatty acids in human peripheral and portal blood: quantitative determination vacuum distillation and gas chromatography. Clin Chim Acta 110, 301-307.

9. Remesy C \& Demigne C (1976) Partition and absorption of valatile fatty acids in the alimentary canal of the rat. Ann Rech Vet 7, 39-55.

10. Storer GB, Trimble RP, Illman RJ, et al. (1983) Effects of dietary oat bran and diabetes on plasma and caecal volatile fatty acids in the rat. Nutr Res 3, 519-526.

11. Wolever TM, Josse RG, Leiter LA, et al. (1997) Time of day and glucose tolerance status affect serum short-chain fatty acid concentrations in humans. Metabolism 46, 805-811.

12. Tazoe H, Otomo Y, Kaji I, et al. (2008) Roles of short-chain fatty acids receptors, GPR41 and GPR43 on colonic functions. J Physiol Pharmacol 59, Suppl. 2, 251-262.
13. Samuel BS, Shaito A, Motoike T, et al. (2008) Effects of the gut microbiota on host adiposity are modulated by the short-chain fatty-acid binding $G$ protein-coupled receptor, Gpr41. Proc Natl Acad Sci US A 105, 16767-16772.

14. Ekblad E \& Sundler F (2002) Distribution of pancreatic polypeptide and peptide YY. Peptides 23, 251-261.

15. Girard J (2008) The incretins: from the concept to their use in the treatment of type 2 diabetes. Part A: incretins: concept and physiological functions. Diabetes Metab 34, 550-559.

16. Tolhurst G, Heffron H, Lam YS, et al. (2012) Short-chain fatty acids stimulate glucagon-like peptide-1 secretion via the G-protein-coupled receptor FFAR2. Diabetes 61, 364-371.

17. Regard JB, Kataoka H, Cano DA, et al. (2007) Probing cell type-specific functions of $\mathrm{Gi}$ in vivo identifies GPCR regulators of insulin secretion. J Clin Invest 117, 4034-4043.

18. Kebede MA, Alquier T, Latour MG, et al. (2009) Lipid receptors and islet function: therapeutic implications? Diabetes Obes Metab 11, Suppl. 4, 10-20.

19. Bahar Halpern K, Veprik A, Rubins N, et al. (2012) GPR41 gene expression is mediated by internal ribosome entry site (IRES)-dependent translation of a bicistronic mRNA encoding GPR40 and GPR41. J Biol Chem 287, 20154-20163.

20. Zaibi MS, Stocker CJ, O'Dowd J, et al. (2010) Roles of GPR41 and GPR43 in leptin secretory responses of murine adipocytes to short chain fatty acids. FEBS Lett $\mathbf{5 8 4}$, 2381-2386.

21. Xiong Y, Miyamoto N, Shibata K, et al. (2004) Short-chain fatty acids stimulate leptin production in adipocytes through the G protein-coupled receptor GPR41. Proc Natl Acad Sci U S A 101, 1045-1050.

22. Hong YH, Nishimura Y, Hishikawa D, et al. (2005) Acetate and propionate short chain fatty acids stimulate adipogenesis via GPCR43. Endocrinology 146, 5092-5099.

23. Kimura I, Inoue D, Maeda T, et al. (2011) Short-chain fatty acids and ketones directly regulate sympathetic nervous system via $G$ protein-coupled receptor 41 (GPR41). Proc Natl Acad Sci U S A 108, 8030-8035.

24. Wargent E, Sennitt MV, Stocker C, et al. (2005) Prolonged treatment of genetically obese mice with conjugated linoleic acid improves glucose tolerance and lowers plasma insulin concentration: possible involvement of PPAR activation. Lipids Health Dis 4, 3.

25. Stocker CJ, Wargent E, O'Dowd J, et al. (2007) Prevention of diet-induced obesity and impaired glucose tolerance in rats following administration of leptin to their mothers. Am J Physiol Regul Integr Comp Physiol 292, R1810-R1818.

26. Weir JB (1949) New methods for calculating metabolic rate with special reference to protein metabolism. J Physiol 109, 1-9.

27. Wang S, Subramaniam A, Cawthorne MA, et al. (2003) Increased fatty acid oxidation in transgenic mice overexpressing UCP3 in skeletal muscle. Diabetes Obes Metab 5, 295-301.

28. Ngala RA, O'Dowd J, Wang SJ, et al. (2008) Metabolic responses to BRL37344 and clenbuterol in soleus muscle and $\mathrm{C} 2 \mathrm{C} 12$ cells via different atypical pharmacologies and $\beta_{2}$-adrenoceptor mechanisms. $\mathrm{Br} J$ Pharmacol 155 395-406.

29. Morgan AD, Carroll ME, Loth AK, et al. (2003) Decreased cocaine self-administration in Kir3 potassium channel subunit knockout mice. Neuropsychopharmacology 28, 932-938.

30. Sleeth ML, Thompson EL, Ford HE, et al. (2010) Free fatty acid receptor 2 and nutrient sensing: a proposed role for fibre, fermentable carbohydrates and short-chain fatty acids in appetite regulation. Nutr Res Rev 23, 135-145. 
31. Butler AA \& Kozak LP (2010) A recurring problem with the analysis of energy expenditure in genetic models expressing lean and obese phenotypes. Diabetes 59, 323-329.

32. Arch JR, Hislop D, Wang SJ, et al. (2006) Some mathematical and technical issues in the measurement and interpretation of open-circuit indirect calorimetry in small animals. Int $J$ Obes (Lond) 30, 1322-1331.

33. Fruebis J, Tsao TS, Javorschi S, et al. (2001) Proteolytic cleavage product of $30-\mathrm{kDa}$ adipocyte complement-related protein increases fatty acid oxidation in muscle and causes weight loss in mice. Proc Natl Acad Sci U S A 98, 2005-2010.

34. Qi Y, Takahashi N, Hileman SM, et al. (2004) Adiponectin acts in the brain to decrease body weight. Nat Med 10, $524-529$

35. Garaulet M, Hernandez-Morante JJ, de Heredia FP, et al. (2007) Adiponectin, the controversial hormone. Public Health Nutr 10, 1145-1150.

36. Warren JM, Simon VA, Bartolini G, et al. (2003) Trans-10, cis-12 CLA increases liver and decreases adipose tissue lipids in mice: possible roles of specific lipid metabolism genes. Lipids 38, 497-504.

37. Liu LF, Purushotham A, Wendel AA, et al. (2007) Combined effects of rosiglitazone and conjugated linoleic acid on adiposity, insulin sensitivity, and hepatic steatosis in highfat-fed mice. Am J Physiol Gastrointest Liver Physiol 292, G1671-G1682.

38. Martin AI, Castillero E, Granado M, et al. (2008) Adipose tissue loss in adjuvant arthritis is associated with a decrease in lipogenesis, but not with an increase in lipolysis. $J$ Endocrinol 197, 111-119.

39. Hwang LL, Wang CH, Li TL, et al. (2010) Sex differences in high-fat diet-induced obesity, metabolic alterations and learning, and synaptic plasticity deficits in mice. Obesity (Silver Spring) 18, 463-469.

40. Garcia-Barrado MJ, Iglesias-Osma MC, Moreno-Viedma V, et al. (2011) Differential sensitivity to adrenergic stimulation underlies the sexual dimorphism in the development of diabetes caused by Irs-2 deficiency. Biochem Pharmacol 81, 279-288.

41. Garg N, Thakur S, McMahan CA, et al. (2011) High fat diet induced insulin resistance and glucose intolerance are gender-specific in IGF-1R heterozygous mice. Biochem Biophys Res Commun 413, 476-480.

42. Taraschenko OD, Maisonneuve IM \& Glick SD (2011) Sex differences in high fat-induced obesity in rats: effects of 18-methoxycoronaridine. Physiol Behav 103, 308-314.

43. Uceyler N, Schutt M, Palm F, et al. (2011) Lack of the serotonin transporter in mice reduces locomotor activity and leads to gender-dependent late onset obesity. Int J Obes (Lond) 34, 701-711.

44. Mayes JS \& Watson GH (2004) Direct effects of sex steroid hormones on adipose tissues and obesity. Obes Rev 5, 197-216.

45. Brown LM \& Clegg DJ (2010) Central effects of estradiol in the regulation of food intake, body weight, and adiposity. J Steroid Biochem Mol Biol 122, 65-73.

46. Loizzo S, Vella S, Loizzo A, et al. (2010) Sexual dimorphic evolution of metabolic programming in non-genetic non-alimentary mild metabolic syndrome model in mice depends on feed-back mechanisms integrity for pro-opiomelanocortin-derived endogenous substances. Peptides 31, $1598-1605$.

47. Justo R, Boada J, Frontera M, et al. (2005) Gender dimorphism in rat liver mitochondrial oxidative metabolism and biogenesis. Am J Physiol Cell Physiol 289, C372-C378.

48. Oh TS, Choi JW, Choi DK, et al. (2011) Gender dimorphism in skeletal muscle proteome between lean and diet-induced obese rats. Cell Physiol Biochem 28, 981-996.

49. Choi DK, Oh TS, Choi JW, et al. (2011) Gender difference in proteome of brown adipose tissues between male and female rats exposed to a high fat diet. Cell Physiol Biochem 28, 933-948.

50. Monjo M, Rodriguez AM, Palou A, et al. (2003) Direct effects of testosterone, 17 beta-estradiol, and progesterone on adrenergic regulation in cultured brown adipocytes: potential mechanism for gender-dependent thermogenesis. Endocrinology 144, 4923-4930.

51. Bjursell M, Admyre T, Goransson M, et al. (2011) Improved glucose control and reduced body fat mass in free fatty acid receptor 2-deficient mice fed a high-fat diet. Am J Physiol Endocrinol Metab 300, E211-E220. 